\title{
THE APRIL MEETING IN EVANSTON
}

The seven hundred fourth meeting of the American Mathematical Society was held at Northwestern University, Evanston, Illinois, on Friday and Saturday, April 27-28, 1973. There were 233 registrants, including 196 members of the Society.

By invitation of the Committee to Select Hour Speakers for Western Sectional Meetings, there were four one-hour addresses. Professor Howard A. Osborn of the University of Illinois spoke Friday morning on Some differential geometry in PL. He was introduced by Professor $\mathbf{J}$. Marshall Osborn. Professor Norman Blackburn of the University of Illinois at Chicago Circle addressed the Society on Friday afternoon, with Professor Paul M. Weichsel presiding. Professor Blackburn's subject was Theorems on counting subgroups of finite p-groups. Professor Alexandra Ionescu-Tulcea of Northwestern University, who was introduced by Professor Neal J. Rothman, spoke Saturday morning. Professor Tulcea's talk was entitled On measurability, pointwise convergence, and compactness. Professor Carl M. Pearcy of the University of Michigan addressed the Society on Saturday afternoon. His topic was Quasitriangular operators and the invariant subspace problem: Some recent progress; he was introduced by Professor Felix E. Browder.

By invitation of the same committee there were six special sessions of selected twenty-minute papers. Professor Richard A. Askey of the University of Wisconsin arranged one such session, on the subject of Special Functions; the speakers were George E. Andrews, Richard A. Askey, Leonard Carlitz, Loyal Durand III, Charles F. Dunkl, Jerry L. Fields, George Gasper, Jr., Walter Gautschi, Willard Miller, Jr., and Frank W. J. Olver. Professor George K. Francis of the University of Illinois at Urbana-Champaign arranged a special session on Closed Curves on Surfaces and in Space; the speakers were Keith D. Bailey, Thomas F. Banchoff, S. J. Blank, Edgar A. Feldman, Francis J. Flaherty, George K. Francis, Benjamin R. Halpern, Morris L. Marx, Michael Menn, Victor T. Norton, Jr., Charles J. Titus, Stephanie F. Troyer, Joel L. Weiner, James H. White, and Leslie C. Wilson. Professor Colin C. Graham of Northwestern University arranged a special session on Commutative Harmonic Analysis; the speakers were Gregory F. Bachelis, John E. Gilbert, Henry Helson, Richard A. Hunt, Robert P. Kaufman, O. Carruth McGehee, Donald E. Ramirez, and Sadihiro Saeki. Professor Wolfgang R. G. Haken of the University of Illinois at Urbana-Champaign arranged a special session on the Four-Color Problem; the speakers were 
Michael O. Albertson, Kenneth I. Appel, Frank Bernhart (replacing Frank Harary), Wolfgang R. G. Haken, Edward F. Moore, and Daniel H. Younger. Professor Kenneth R. Mount of Northwestern University arranged a special session on Singularities of Varieties and Mappings; the speakers were Shreeram Abhyankar, Joseph Lipman, Tzoung-Tsieng Moh, Peter P. Orlik, and Joel L. Roberts. Professor Steven Orey of the University of Minnesota arranged a special session on Sample Functions of Stochastic Processes; the speakers were Bert E. Fristedt, Joseph Horowitz, Robert P. Kaufman, Michael B. Marcus, and Michael J. Wichura.

There were five informal sessions, each one being associated with one of the above special sessions of selected twenty-minute papers. Professor Richard A. Askey of the University of Wisconsin conducted an informal session on Handbooks of Special Functions. Professor Colin C. Graham of Northwestern University conducted an informal session on Commutative Harmonic Analysis. Professor Wolfgang R. G. Haken of the University of Illinois at Urbana-Champaign conducted an informal session on the Four-Color Problem. Professor Kenneth R. Mount of Northwestern University conducted an informal session on Singularities of Varieties and Mappings. Finally, Professor William F. Pohl of the University of Minnesota conducted a problem session as part of the special session on Closed Curves on Surfaces and in Space.

There were four sessions of contributed ten-minute papers, for which Professors Meyer Dwass, Amassa C. Fauntleroy, Stephen D. Fisher, Joshua A. Leslie, and Alexandra Ionescu-Tulcea served as presiding officers. Of the 29 ten-minute papers listed in the program, 2 were presented by title; two late papers were added to the program, so exactly 29 ten-minute paper were actually presented.

URBANA, ILLINOIS

Paul T. Bateman Associate Secretary 